\title{
Bactérias zoonóticas isoladas de Passeriformes silvestres recuperados do tráfico de animais no estado do Ceará/Brasil
}

\author{
[Zoonotic bacteria isolated from wild Passeriformes recovered from animal trafficking in \\ the State of Ceará/Brazil]
F.C. Gaio ${ }^{1}$, E.S. Lopes ${ }^{1}$, B.P. Lima ${ }^{1}$, C.C. Carmo ${ }^{1}$, A.R. Marques ${ }^{1}$, F.R. Oliveira ${ }^{1}$, M.S.M.G. Amaral ${ }^{2}$, N.M. Pascoal Filho ${ }^{1}$, A.S. Carreira ${ }^{1}$, A.J.F. Beleza ${ }^{1}$, R.S.C. Teixeira ${ }^{1}$, A. Havt ${ }^{2}$, W.C. Maciel ${ }^{1 *}$

${ }^{1}$ Universidade Estadual do Ceará - Fortaleza, CE

${ }^{2}$ Universidade Federal do Ceará - Fortaleza, CE

\begin{abstract}
RESUMO
A ordem dos Passeriformes é uma das mais pressionadas pelas ações antrópicas, especialmente as relativas ao tráfico de animais, que, devido às más condições de manejo e higiênico-sanitárias, favorecem a infecção dos espécimes por patógenos virulentos e zoonóticos, como cepas de Escherichia coli e Salmonella spp., cujo isolamento em suabes cloacais, bem como a análise dos genes de virulência das cepas de E. coli foram objetivos do estudo. Para isso, 120 Passeriformes silvestres nativos, recebidos pelo Cetas/CE, foram avaliados individualmente. As cepas isoladas foram submetidas a teste de disco difusão para determinação da sensibilidade aos antimicrobianos. Em etapa posterior, foi realizada PCR para a detecção de oito genes de virulência dos principais patotipos diarreiogênicos de E. coli. Quanto aos resultados, nenhuma cepa de Salmonella spp. foi isolada, no entanto a ocorrência de E. coli foi de 40,8\%. Foi observada elevada resistência, principalmente aos antimicrobianos tetraciclina, ampicilina e sulfazotrim, ocorrendo multirresistência em 42,8\% das cepas. Pela análise molecular, foram diagnosticados quatro entre os nove genes pesquisados, com a identificação de EPEC típicas, EPEC atípicas, ETEC, EHEC e EAEC. Os resultados apontam para a importância de Passeriformes como possíveis disseminadores de zoonoses.
\end{abstract}

Palavras-chave: Passeriformes silvestres, tráfico de animais, zoonoses, Escherichia coli, saúde pública

\begin{abstract}
The order Passeriformes is one of the most pressured by anthropic actions, especially those related to animal trafficking. Due to poor sanitary and hygienic conditions, the infection of the specimens is favored by virulent and zoonotic pathogens such as strains of Escherichia coli and Salmonella spp., whose isolation in cloacal swabs as well as the analysis of the virulence genes of E. coli strains were the objectives of the study. For this, 120 native wild Passeriformes, received by CETAS/CE were individually evaluated. The isolated strains were submitted to diffusion disc test to determine sensitivity to antimicrobials. In a later stage, PCR was performed for the detection of eight virulence genes from the main E. coli diarrhoeagenic pathogens. Regarding the results, no strain of Salmonella spp. was isolated; however, the occurrence of E. coli was 40.8\%. High resistance was observed, mainly to the antimicrobials Tetracycline, Ampicillin and Sulfazotrim, with multi-resistance in $42.8 \%$ of the strains. By molecular analysis, four of the nine genes were diagnosed, identifying typical EPEC, atypical EPEC, ETEC, EHEC and EAEC. The results point to the importance of Passeriformes as possible disseminators of zoonoses.
\end{abstract}

Keywords: wild passeriformes, animal trafficking, zoonosis, Escherichia coli, public health

Recebido em 13 de junho de 2017

Aceito em 25 de janeiro de 2019

*Autor para correspondência (corresponding author)

E-mail: william.maciel@uol.com.br 


\section{INTRODUÇÃO}

A caça e o comércio de animais silvestres oriundos de seu habitat natural são atividades proibidas no Brasil, cerceada por órgãos do governo nos níveis municipal, estadual e federal (Oliveira et al., 2018), entretanto essa contravenção ainda retira cerca de 38 milhões de animais do ambiente nativo (Mendes, 2018). Além disso, o impacto dessa atividade resulta em um índice de mortalidade que pode alcançar $90 \%$ dos animais em razão das más condições de captura e transporte (Pagano et al., 2009).

Quando os espécimes explorados ilegalmente retornam ao poder do Estado, por meio de apreensões ou por entregas voluntárias, são direcionados aos Centros de Triagem de Animais Silvestres (Cetas), Centros de Reabilitação de Animais Silvestres (Cras) ou empreendimentos afins (Guidelines..., 2002; Matias et al., 2012). A classe de animais mais recebida nesses centros é a das aves, sendo a ordem dos Passeriformes a mais abundante em quantidade de indivíduos e número de espécies (Freitas et al., 2015; Regueira e Bernard, 2012). Após a recepção, os animais devem ser submetidos a protocolos de triagem e reabilitação, visando à sanidade e ao bem-estar animal, como passar por quarentena, exames clínicos e testes comportamentais (Guidelines..., 2002).

Nesse contexto, a adoção de práticas que visem à segurança sanitária, como a realização de exames bacteriológicos, é fundamental, pois as aves provenientes do tráfico passam por situações estressantes e são mantidas em ambientes insalubres, condições as quais favorecem a contaminação oral-fecal dos espécimes por bactérias da família Enterobacteriaceae, devido ao potencial e ao patogênico zoonótico, Salmonella spp. e Escherichia coli, especialmente as cepas diarreiogênicas (EPEC, STEC, EIEC, EAEC, ETEC), as quais possuem grande relevância para a saúde pública (MariettoGonçalves et al., 2010; Braconaro et al., 2015; Matias et al., 2016).

Diante do exposto e devido à relevância do tema quanto à escassez de informações, o objetivo deste estudo foi determinar a ocorrência de $E$. coli e Salmonella spp., identificar o perfil de sensibilidade dos isolados aos antimicrobianos, bem como avaliar a presença de genes de virulência em cepas de $E$. coli provenientes de Passeriformes silvestres recuperados do tráfico de animais e mantidos no Cetas/CE.

\section{MATERIAL E MÉTODOS}

Foram realizados suabes cloacais em 120 Passeriformes silvestres nativos, que foram recebidos pelo Centro de Triagem de Animais Silvestres - Cetas do Ibama, situado em Fortaleza, Ceará, Brasil, no período de maio a setembro de 2016. As aves pertenciam a 25 espécies e a quatro famílias: Thraupidae, Turdidae, Cardinalidae e Icteridae (Tab. 1). Este estudo foi submetido ao Sisbio e aprovado por ele (53106-1), assim como pelo Comitê de Ética para Uso de Animais (Ceua) da Universidade Estadual do Ceará, sob o número 2204213.

Após a coleta, os suabes foram acondicionados em tubos de ensaio contendo $5 \mathrm{~mL}$ de água peptonada (Himedia, Mumbai, Índia), os quais foram dispostos em caixa isotérmica com gelo reciclável e transportados ao Laboratório de Estudos Ornitológicos da Universidade Estadual do Ceará, a fim de proceder ao isolamento e à identificação morfológica e bioquímica das cepas bacterianas. O protocolo de isolamento de E. coli e Salmonella spp. foi executado segundo as recomendações de Koneman et al. (2012).

A incubação das amostras ocorreu em estufa bacteriológica, por $24 \mathrm{~h} / 37^{\circ} \mathrm{C}$ (tempo e temperatura padrão utilizados em todas as etapas subsequentes). Em seguida, $1 \mathrm{~mL}$ da solução foi transferido para tubos contendo caldo selenito cistina (Himedia, Mumbai, Índia) e para tubos com caldo BHI (Brain Heart Infusion) (Himedia, Mumbai, Índia). Posteriormente, o plaqueamento ocorreu com o auxilio de alça de platina, quando alíquotas dos caldos foram semeadas em placas de Petri contendo ágar MacConkey ou ágar eosina azul de metileno (EMB) e em placas com ágar entérico Hektoen e Salmonella-Shigella.

As colônias foram selecionadas (aspecto morfológico e fermentativo) e transferidas para tubos contendo ágar tríplice açúcar ferro (TSI), quando foram iniciados os testes bioquímicos. Após 24h, foram selecionadas as cepas de bactérias que expressaram as características clássicas fermentativas de E. coli e Salmonella spp., as quais foram submetidas aos testes ágar lisina ferro (LIA), ágar SIM (sulfeto, indol e 
motilidade), reação de Voges-Proskauer, vermelho de metila, citrato, malonato e ureia. Procedeu-se à leitura e interpretação do perfil bioquímico para identificação das bactérias, de acordo com os parâmetros apresentados por Bergey e Holt (1994) e Koneman et al. (2012).

Tabela 1. Passeriformes alojados no Centro de Triagem de Animais Silvestres/CE e submetidos à análise microbiológica

\begin{tabular}{|c|c|c|c|c|}
\hline Nome comum & Nome científico & Família & $\begin{array}{l}\text { Quantidade } \\
\text { (n) }\end{array}$ & $\begin{array}{c}\text { Porcentagem } \\
\text { em relação ao } \\
\text { número total } \\
\text { de aves }(\%)\end{array}$ \\
\hline Bicudo & Cyanoloxia brissonii (Lichtenstein, 1823) & Cardinalidae & 04 & 3,3 \\
\hline Azulão & Molothrus bonariensis (Gmelin, 1789) & Icteridae & 01 & 0,8 \\
\hline Corrupião & Icterus jamacaii (Gmelin, 1788) & Icteridae & 03 & 2,5 \\
\hline Graúna & Gnorimopsar chopi (Vieillot, 1819) & Icteridae & 04 & 3,3 \\
\hline Papa-arroz & Chrysomus ruficapillus (Vieillot, 1819) & Icteridae & 02 & 1,7 \\
\hline Primavera & Icterus cayanensis (Linnaeus, 1766) & Icteridae & 01 & 0,8 \\
\hline Sabiá-da-praia & Mimus gilvus (Vieillot, 1807) & Mimidae & 01 & 0,8 \\
\hline Abre-e-fecha & Lanio pileatus (Wied, 1821) & Thraupidae & 04 & 3,3 \\
\hline Bigodeiro & Sporophila lineola (Linnaeus, 1758) & Thraupidae & 07 & 5,8 \\
\hline Caboclinho & Sporophila bouvreuil (Statius Muller, 1776) & Thraupidae & 01 & 0,8 \\
\hline Canário-da-terra & Sicalis flaveola (Linnaeus, 1766) & Thraupidae & 04 & 3,3 \\
\hline Canário-pirrita & Sicalis luteola (Sparrman, 1789) & Thraupidae & 03 & 2,5 \\
\hline Cardeal & Paroaria coronata (Miller, 1776) & Thraupidae & 01 & 0,8 \\
\hline $\begin{array}{l}\text { Galo-de- } \\
\text { campina }\end{array}$ & Paroaria dominicana (Linnaeus, 1758) & Thraupidae & 47 & 39 \\
\hline Golinha & Sporophila albogularis (Spix, 1825) & Thraupidae & 06 & 5,0 \\
\hline Papa-capim & Sporophila nigricollis (Vieillot, 1823) & Thraupidae & 10 & 8,3 \\
\hline Pipira-preta & Tachyphonus rufus (Boddaert, 1783) & Thraupidae & 01 & 0,8 \\
\hline Saí-andorinha & Tersina viridis viridis (Illiger, 1811) & Thraupidae & 01 & 0,8 \\
\hline $\begin{array}{l}\text { Sanhaçu- } \\
\text { cinzento }\end{array}$ & Tangara sayaca (Linnaeus, 1766) & Thraupidae & 02 & 1,7 \\
\hline $\begin{array}{l}\text { Sanhaçu-do- } \\
\text { coqueiro }\end{array}$ & Tangara palmarum (Wied, 1823) & Thraupidae & 03 & 2,5 \\
\hline Sanhaçu-macaco & Tangara cayana (Linnaeus, 1766) & Thraupidae & 02 & 1,7 \\
\hline Tiziu & Volatinia jacarina (Linnaeus, 1766) & Thraupidae & 03 & 2,5 \\
\hline Trinca-ferro & $\begin{array}{l}\text { Saltator similis (d'Orbigny e Lafresnaye, } \\
1837 \text { ) }\end{array}$ & Thraupidae & 01 & 0,8 \\
\hline Sabiá-da-mata & Turdus fumigatus (Lichtenstein, 1823) & Turdidae & 04 & 3,3 \\
\hline Sabiá-laranjeira & Turdus rufiventris (Vieillot, 1818) & Turdidae & 04 & 3,3 \\
\hline \multicolumn{3}{|c|}{ Total de espécimes investigadas } & 120 & 100,0 \\
\hline
\end{tabular}

Para a realização do teste de susceptibilidade aos antimicrobianos, as cepas de Escherichia coli foram repicadas em tubos contendo $5 \mathrm{~mL}$ de caldo BHI (Brain Heart Infusion) e incubadas a $37^{\circ} \mathrm{C} / 24 \mathrm{~h}$. Após a incubação, cada amostra foi plaqueada em ágar MacConkey para a determinação de pureza da cepa. Confirmada essa etapa, colônias foram retiradas da placa e inoculadas em tubos contendo $2 \mathrm{~mL}$ de solução salina esterilizada. Em seguida, as culturas diluídas na concentração 0,5 da escala de McFarland foram semeadas com o auxílio de suabes estéreis, em placas contendo ágar Mueller-Hinton e, após secagem da superfície do meio, foram depositados os discos contendo os seguintes antimicrobianos: ampicilina $(10 \mu \mathrm{g})$, ceftiofur $\quad(30 \mu \mathrm{g}), \quad$ ciprofloxacina $\quad(5 \mu \mathrm{g})$, sulfazotrim $(25 \mu \mathrm{g})$, polimixina B $(300 \mu \mathrm{g})$, gentamicina $(10 \mu \mathrm{g})$, ácido nalidíxico $(30 \mu \mathrm{g})$, tetraciclina $(30 \mu \mathrm{g})$, azitromicina $(15 \mu \mathrm{g})$ enrofloxacina $(5 \mu \mathrm{g})$, estreptomicina $(300 \mu \mathrm{g}) \mathrm{e}$

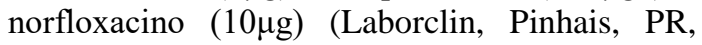
Brasil). A leitura foi realizada após 18 a $24 \mathrm{~h}$ de incubação, por meio da medição dos halos de inibição. Os testes de difusão de disco foram avaliados segundo as recomendações do Clinical and Laboratory Standards Institute (Performance..., 2014), e os isolados foram classificados quanto à resistência como bactérias sensíveis, de resistência intermediária e de resistência plena, quando não havia formação de halo. Foi considerado bactérias com resistência 
total ou bactérias resistentes o somatório dos micro-organismos com resistência plena e intermediária. Empregou-se o termo multirresistência para classificar as cepas resistentes a, no mínimo, três antimicrobianos. A cepa de Escherichia coli ATCC 25922 foi utilizada como controle.

O diagnóstico das cepas de Escherichia coli diarreiogênicas isoladas de suabes cloacais foi baseado na presença de oito genes de virulência de diagnóstico de cinco patotipos de E. coli. Para isso, de cada isolado foram recuperadas de três a quatro colônias de cepas anteriormente semeadas em placas contendo ágar MacConkey. Para o teste de PCR, cada amostra representou um pool formado de colônias provenientes de quatro ou cinco isolados diferentes. Foram utilizadas sequências de iniciadores já descritas, sendo: os genes stx1 (348 pb) e stx2 $(584 \mathrm{pb})$ para identificação de E. coli produtora de toxina Shiga - STEC; eltB (508 pb) e estA (147pb) para $E$. coli enterotoxigênica - ETEC; eaeA $(881 \mathrm{pb})$ e bfpA (300pb) para E. coli enteropatogênica EPEC; ipaH (483pb) para E.coli enteroinvasiva EIEC; e aatA (630pb) e aaiC $(215 \mathrm{pb})$ para $E$. coli enteroagregativa - EAEC, conforme a Tab. 2 (Taniuchi et al., 2012). As cepas EAEC 042, EHEC O157:H7, EIEC O124, EPEC 2348/69 e ETEC H10407 foram utilizadas como controles positivos das reações.

Tabela 2. Genes e iniciadores utilizados para identificação de E. coli diarreiogênicas isoladas dos Passeriformes alojados no Centro de Triagem de Animais Silvestres/CE

\begin{tabular}{|c|c|c|c|}
\hline Genes & Descrição dos genes alvo & Pares de iniciadores oligonucleotídicos $\left(5^{\prime}-3^{\prime}\right)$ & Amplicons (pb) \\
\hline stx 1 & STEC & $\begin{array}{l}\text { ACTTCTCGACTGCAAAGACGTATG } \\
\text { ACAAATTATCCСCTGAGCCACTATC }\end{array}$ & 348 \\
\hline stx 2 & STEC & $\begin{array}{l}\text { GGCACTGTCTGAAACTGCTCCG } \\
\text { TCGCCAGTTATCTGACATTCTG }\end{array}$ & 584 \\
\hline elt $\mathrm{B}$ & ETEC & $\begin{array}{l}\text { TTCCCACCGGATCACCAA } \\
\text { CAACCTTGTGGTGCATGATGA }\end{array}$ & 508 \\
\hline est A & ETEC & $\begin{array}{l}\text { TTCACCTTTCGCTCAGGATG } \\
\text { AGCACCCGGTACAAGCAG }\end{array}$ & 147 \\
\hline eae A & EPEC & $\begin{array}{l}\text { GTAAAGTCCGTTACCCCAACCTG } \\
\text { CAAAGCGCACAAGACTACCA }\end{array}$ & 881 \\
\hline bfp A & EPEC & $\begin{array}{l}\text { GGAAGTCAAATTCATGGGGG } \\
\text { GGAATCAGACGCAGACTGGT }\end{array}$ & 300 \\
\hline$i p a \mathrm{H}$ & $E I E C$ & $\begin{array}{l}\text { CCTTTTCCGCGTTCCTTGA } \\
\text { CGGAATCCGGAGGTATTGC }\end{array}$ & 483 \\
\hline aat $\mathrm{A}$ & $E A E C$ & $\begin{array}{l}\text { CTGGCGAAAGACTGTATCAT } \\
\text { TTTTGCTTCATAAGCCGATAGA }\end{array}$ & 630 \\
\hline aaiC & $E A E C$ & $\begin{array}{l}\text { ATTGTCCTCAGGCATTTCAC } \\
\text { ACGACACCCCTGATAAACAA }\end{array}$ & 215 \\
\hline
\end{tabular}

Adaptação de Taniuchi et al. (2012).

A extração de DNA ocorreu pelo método de ebulição (Lima et al., 2013). As reações de PCR foram realizadas utilizando-se a enzima GoTaqGreen (Promega) e iniciadores a 0,4uM em termociclador MyCycler Thermal Cycler (Biorad, CA, EUA), com o seguinte protocolo: $95^{\circ} \mathrm{C}$ por $15 \mathrm{~min} ; 40$ ciclos de $95^{\circ} \mathrm{C}$ por $30 \mathrm{~s}$, $57^{\circ} \mathrm{C}$ por $30 \mathrm{~s} \mathrm{e} 72^{\circ} \mathrm{C}$ por $1 \mathrm{~min}$; e $72^{\circ} \mathrm{C}$ por 10 min. Os produtos foram visualizados a partir de eletroforese em gel de agarose a $2 \%$, sendo corados por brometo de etídeo e identificados em transiluminador ChemicDoc XRS System (Biorad, CA, EUA).

\section{RESULTADOS E DISCUSSÃO}

A taxa de isolamento de $E$. coli obtida neste estudo foi de 40,8\% (49/120), podendo ser considerada elevada, visto que pássaros de hábitos alimentares granívoros e frugívoros saudáveis tendem a apresentar microbiota entérica unicamente composta por bactérias Gram-positivas, e a detecção de Gram-negativas indica a ruptura nas condições de homeostase (Glonder, 1981). Aparentemente, os Passeriformes expostos aos ambientes insalubres do comércio ilegal estão mais propensos à 
contaminação por bactérias Gram-negativas, especialmente por E. coli, do que aves mantidas em cativeiro, fato que pode ser evidenciado pelo estudo de Horn et al. (2015), os quais detectaram, em 387 suabes cloacais de canáriosbelgas (Serinus canaria), clinicamente saudáveis e criados em gaiolas, um percentual de apenas $3,62 \%$, taxa inferior à obtida no presente trabalho.

Outros estudos envolvendo pesquisa de E. coli de suabes cloacais em aves provenientes do comércio ilegal trazem resultados diversificados quanto ao percentual de isolamento. Matias et al. (2016) constataram taxa de positividade de $50,48 \%$ (52/103), resultado bem próximo aos encontrados nesta pesquisa. Braconaro et al. (2015) investigaram a microbiota entérica de 253 pássaros silvestres, pertencentes a 34 espécies diferentes, mantidos em Centro de Reabilitação em São Paulo/SP, e constataram 10,7\% (27/253) de isolamento de E. coli. Os resultados de Cunha et al. (2016), por outro lado, revelam percentuais mais elevados. Esses pesquisadores averiguaram suabes cloacais e de fezes de 49 espécimes de Passeriformes da família Thraupidae, sendo 30 de Paroaria dominicana e 19 de $P$. coronata, provenientes do tráfico e mantidos no Centro de Recuperação de Animais Silvestres do Parque Ecológico do Tietê (Cras/Pet), localizado em São Paulo/SP, e identificaram 85,7\% (42/49) de amostras positivas para E. coli.

Neste estudo, todos os suabes cloacais realizados nos Passeriformes do Cetas/CE foram negativos para Salmonella spp. Apesar da ausência do patógeno, os cuidados sanitários não devem ser descartados, visto que, em determinadas circunstâncias, essa bactéria pode ser eliminada nas fezes das aves de maneira intermitente (Lopes et al., 2014). Adicionalmente, as pesquisas de suabes cloacais envolvendo Salmonella em pássaros resgatados do tráfico mostram que a ocorrência desse microrganismo é baixa. Matias et al. (2016) investigaram pássaros mantidos no Cetas de Seropédica (RJ) e observaram a presença de apenas uma cepa $(0,97 \%)$ de Salmonella ser. Typhimurium, isolada de espécime de Sporophila falcirostris, e duas cepas de Salmonella ser. Panama (1,94\%), em dois espécimes de Chrysomus ruficapillus. Em São Paulo/SP, Cunha et al. (2016) detectaram isolamento de Salmonella spp. em dois espécimes de Paroaria dominicana, com taxa de isolamento de 4\% (2/49).

Nesta pesquisa, no que se refere à resistência antimicrobiana, pode-se observar que todos os isolados de E. coli foram resistentes à tetraciclina e à norfloxacina, tendo $53,1 \%$ das amostras manifestado resistência total à primeira droga, maior percentual entre todos os antibióticos testados. Por sua vez, a taxa de resistência plena à norfloxacina foi de $12,2 \%$, sendo de $100 \%$ a da resistência total. Taxas de resistência total igualmente elevada foram observadas para ampicilina, sulfazotrim e gentamicina, que, nos três casos, obtiveram percentuais de $98,0 \%$ (Tab. 3).

Tabela 3. Frequência de resistência de cepas E. coli isoladas de Passeriformes recebidos no Cetas/CE

\begin{tabular}{lcccc} 
& Sensíveis & \multicolumn{2}{c}{ Diferentes Graus de Resistência } & Resistência \\
\cline { 3 - 4 } & $\mathrm{n}(\%)$ & $\mathrm{Intermediária}$ & $\mathrm{T}$ & $\mathrm{T}(\%)$ \\
$\mathrm{nnyy}$ & $1(2,0)$ & $25(51,0)$ & $\mathrm{n}(\%)$ & $\mathrm{n}(\%)$ \\
\hline Ampicilina & - & $23(46,9)$ & $23(46,9)$ & $48(98,0)$ \\
Tetraciclina & $4(8,2)$ & $39(79,6)$ & $6(12,2)$ & $49(100,0)$ \\
Ciprofloxacina & $1(2,0)$ & $27(55,1)$ & $21(42,9)$ & $48(91,8)$ \\
Sufazotrim & $1(2,0)$ & $48(98,0)$ & - & $48(98,0)$ \\
Gentamicina & $14(28,6)$ & $28(57,1)$ & $7(14,3)$ & $35(77,8)$ \\
Enrofloxacina & $3(6,1)$ & $40(81,6)$ & $6(12,2)$ & $46(95,8)$ \\
Estreptomicina & $22(44,9)$ & $19(38,8)$ & $41(83,7)$ \\
Ácido nalidíxico & $8(16,3)$ & $43(87,8)$ & $6(12,2)$ & $49(100,0)$ \\
Norfloxacina & - & $16(32,7)$ & $4(8,2)$ & $20(40,8)$ \\
Azitromicina & $29(59,2)$ & $46(93,9)$ & $1(2,0)$ & $47(95,9)$ \\
Polimixina & $2(4,1)$ & $29(59,2)$ & $4(8,2)$ & $33(67,3)$ \\
Ceftiofur & $16(32,7)$ & &
\end{tabular}


Os estudos que associam resistência antimicrobiana a cepas de $E$. coli isoladas de Passeriformes provenientes do tráfico de animais ainda são escassos, por isso o real impacto da comercialização e das criações ilegais dessas aves, principalmente no que se refere ao uso indiscriminado de antimicrobianos e ao seu papel na disseminação dessas bactérias resistentes, ainda precisa ser elucidado. No entanto, Braconato et al. (2015) mostraram que as cepas de E. coli isoladas de Passeriformes confiscados do tráfico apresentaram taxa de resistência de $100,0 \%$ e $7,4 \%$ para ampicilina e norfloxacina, respectivamente. A taxa relacionada à ampicilina foi similar à observada nas bactérias isoladas das aves do Cetas/CE (98,0\%), entretanto divergente quando comparada à norfloxacina (100,0\%). Outro importante resultado que destoa na comparação entre o presente estudo e o de Braconaro et al. (2015) se refere à eficácia da azitromicina, visto que apenas $28,6 \%$ das cepas isoladas foram sensíveis a esse antimicrobiano, tendo sido, nos isolados obtidos das aves do Cetas/CE, o antimicrobiano que apresentou maior grau de sensibilidade $(59,2 \%)$.

Horn et al. (2015) avaliaram isolados de E. coli provenientes de canários-belgas (Serinus canaria) de criadores que mantinham preocupação em utilizar adequados protocolos sanitários, manejo nutricional e ambientação, e detectaram taxa de resistência antimicrobiana de $64 \%$ e $48 \%$ para sulfonamidas e tetraciclina, respectivamente. As taxas de resistência em relação a esses antibióticos detectadas com base nas amostras oriundas dos Passeriformes do Cetas/CE foram superiores e podem ter uma relação com possíveis falhas no manejo sanitário das aves antes do resgastes.
Relatos científicos acerca de aspectos microbiológicos de psitacídeos recuperados do tráfico de animais são mais comuns e, da mesma forma, trazem resultados variáveis em relação à resistência antimicrobiana e aos fármacos mais eficazes. Invariavelmente, em todas as pesquisas, ocorre elevada taxa de resistência antimicrobiana em relação a uma ou mais drogas específicas. Marietto-Gonçalves et al. (2010) verificaram alta resistência à sulfonamida $(83,0 \%)$ em cepas de E. coli obtidas de psitacídeos apreendidos em São Paulo, enquanto Hidasi et al. (2013), ao analisarem psitacídeos do Cetas/GO, detectaram as maiores taxas de resistência para tetraciclina $(64,5 \%)$ e doxiciclina (69,2\%). Apesar da necessidade de mais investigações, as elevadas taxas de resistências para diferentes antimicrobianos, observadas em cepas de E. coli isoladas de aves provenientes do tráfico de animais silvestres, sugerem relação à utilização indiscriminada dessas drogas. Além disso, a exposição das aves aos ambientes insalubres facilita a transmissão de genes por bactérias resistentes.

Das cepas de E. coli isoladas, 61,2\% apresentaram-se resistentes a, no mínimo, três antibióticos, o que as classifica como multirresistentes (Tab. 4). Essa taxa pode ser considerada elevada quando comparada à verificada por Horn et al. (2015) em Serinus canaria, cujo valor encontrado foi de $40,2 \%$. No entanto, os resultados detectados nos pássaros dos Cetas/CE são similares aos de Lopes et al. (2015), que identificaram multirresistência em $61,7 \%$ das cepas de E. coli isoladas de psitacídeos oriundos do comércio ilegal, dado que reforça o malefício das criações ilegais sobre o ponto de vista sanitário para diferentes espécies aviárias.

Tabela 4. Padrão de resistência das cepas de E. coli isoladas de Passeriformes recebidos no Cetas/CE

\begin{tabular}{lccc}
\hline $\begin{array}{l}\text { Número de } \\
\text { antibióticos }\end{array}$ & No-de resistência total $(\%)$ & $\begin{array}{c}\text { Número de } \\
\text { antibióticos }\end{array}$ & $\begin{array}{c}\text { Noo-de resistência total } \\
(\%)\end{array}$ \\
\hline 0 & $3(6,1)$ & 5 & $2(4,1)$ \\
Pelo menos 1 & $46(93,8)$ & 6 & $4(8,2)$ \\
1 & $14(28,6)$ & 7 & $3(6,1)$ \\
$>2^{*}$ & $30(61,2)^{*}$ & 8 & $4(8,2)$ \\
2 & $2(4,1)$ & 9 & $3(6,1)$ \\
3 & $3(6,1)$ & 10 & $1(2,0)$ \\
4 & $9(18,4)$ & 11 & $1(2,0)$ \\
\hline
\end{tabular}

* Valores associados à taxa de bactérias multirresistentes. 
Quanto à análise dos genes de virulência, os isolados de E. coli apresentaram positividade para importantes fatores, visto que foram detectados os genes aaiC, stx 1 e eae A associado ou não ao $b f p \mathrm{~A}$ (Tab. 5). De maneira similar, Matias et al. (2016) identificaram, em cinco isolados de E. coli, o gene eaeA, nas espécies:
Chrysomus ruficapillus, Sporophila albogularis, Turdus albicollis, Tangara sayaca e Gnorimopsar chopi. O gene stx 2 foi detectado em um isolado de Gnorimopsar chopi. Braconaro et al. (2015) isolaram apenas um gene de virulência em 27 isolados de $E$. coli.

Tabela 5. Relação entre amostras, família aviária da qual a cepa foi isolada, genes detectados e classificação do patotipo

\begin{tabular}{|c|c|c|c|c|}
\hline $\begin{array}{l}\text { № } \\
\text { Pool }\end{array}$ & $\begin{array}{c}\text { № de } \\
\text { amostras }\end{array}$ & Família & Gene (s) detectado(s) & Patotipo \\
\hline 01 & 5 & Thraupidae & aaiC & EAEC \\
\hline 02 & 5 & Turdidae & aaiC & EAEC \\
\hline 03 & 4 & Thraupidae & $e a e \mathrm{~A}, b f p \mathrm{~A}, s t x 1$, aai $\mathrm{C}$ & $\begin{array}{l}\text { EPEC típica, EAEC, } \\
\text { EHEC }\end{array}$ \\
\hline 04 & 4 & $\begin{array}{l}\text { Cardinalidae/ } \\
\text { Thraupidae }\end{array}$ & aaiC & EAEC \\
\hline 05 & 4 & Thraupidae & eae $\mathrm{A}$, aaiC & $\begin{array}{l}\text { EPEC atípica, EAEC, } \\
\text { ETEC }\end{array}$ \\
\hline 06 & 4 & Thraupidae & eae $\mathrm{A}$, aaiC & EPEC atípica, EAEC \\
\hline 07 & 4 & Icteridae & $\varnothing$ & $\varnothing$ \\
\hline 08 & 5 & Thraupidae & aaiC & EAEC \\
\hline 09 & 5 & Thraupidae & eae $\mathrm{A}$, aaiC & EPEC atípica, EAEC \\
\hline 10 & 4 & Thraupidae & eae $\mathrm{A}$, aaiC & EPEC atípica, EAEC \\
\hline 11 & 5 & Thraupidae & eae $\mathrm{A}$, aaiC & EPEC atípica, EAEC \\
\hline
\end{tabular}

Resultados expressivos foram descritos por Reple et al. (2015), que coletaram amostras de 448 psitacídeos, de espécies domésticas e silvestres, no estado de São Paulo, e identificaram que $14,6 \%$ (7/48) das cepas de $E$. coli apresentavam os genes eae $\mathrm{A}$ e $b f p \mathrm{~A}$, o que as classifica como EPEC típicas e 10,42\% como EPEC atípicas (5/48). Também foram encontradas $54,5 \%$ (6/11) de STEC em periquitos-australianos (Melopsittacus undulatus). $\mathrm{Na}$ região metropolitana de Fortaleza, Lima (2016) analisou 182 amostras de calopsitas (Nymphicus hollandicus) mantidas em diversos ambientes (cativeiro domiciliar, lojas de animais, entre outros) e diagnosticou apenas uma cepa de EPEC típica. Em 78 amostras de psitacídeos silvestres, mantidos no Cetas/CE, Lopes et al (2018) observaram que $11(14,1 \%)$ foram positivas para os genes eaeA e $b f p \mathrm{~A}$ (com ausência de $s t x$ ), o que as classificou como EPEC típicas e nove $(11,5 \%)$ foram consideradas EPEC atípicas, por apresentarem apenas o gene eaeA, tendo sido ambos os patotipos isolados no presente estudo. Essas duas pesquisas realizadas com psitacídeos domésticos e silvestres, respectivamente, apontam que essas aves podem ser portadoras de cepas de $E$. coli virulentas. No entanto, comparando os resultados verificados em Passeriformes recuperados do tráfico de animais no estado do Ceará com resultados obtidos em estudos similares realizados em outros estados e com pesquisas em psitacídeos domésticos e silvestres no estado do Ceará, infere-se que os resultados atribuídos às cepas de E. coli isoladas dos pássaros do CetaS/CE foram sobremaneira relevantes, pois foi detectada a presença de EPEC típica, EPEC atípica, EHEC, ETEC e EAEC, de modo que foram diagnosticados quatro entre os oito genes pesquisados.

\section{CONCLUSÃO}

O presente estudo apontou que as amostras de suabes cloacais oriundas de Passeriformes provenientes do tráfico de animais silvestres foram negativas para Salmonella, entretanto verificou-se um elevado percentual de isolados de E. coli, assim como alta taxa de resistência aos antimicrobianos testados, além da detecção de genes de virulência de relevância para a saúde pública, eaeA, bfp A, aaiC e stx 1 . Em razão da possibilidade do carreamento de importantes agentes patogênicos, as aves provenientes do 
comércio ilegal, mesmo que clinicamente saudáveis, devem ser investigadas no âmbito microbiológico, pois bactérias com potencial zoonótico podem representar uma significativa ameaça tanto à saúde humana quanto à saúde animal.

\section{REFERÊNCIAS}

BERGEY, D.H.; HOLT, J. Bergey's manual of determinative bacteriology. 9.ed. Baltimore: William \& Wilkis, 1994. p.787.

BRACONARO, P.; SAIDENBERG, A.B.S.; BENITES, N.R. et al. Detection of bacteria and fungi and assessment of the molecular aspects and resistance of Escherichia coli isolated from confiscated passerines intended for reintroduction programs. Microb. Pathog., v.88, p.65-72, 2015.

CUNHA, M.P.V.; GUIMARÃES, M.B.; DAVIES, Y.M. et al. Bactérias Gram-negativas em cardeais (Paroaria coronata e Paroaria dominicana) apreendidos do tráfico de animais silvestres. Braz. J. Vet. Res. Anim. Sci., v.53, p.107-111, 2016.

FREITAS, A.C.P.; OVIEDO-PASTRANA, M.E.; VILELA, D.A.R. et al. Diagnóstico de animais ilegais recebidos no centro de triagem de animais silvestres de Belo Horizonte, Estado de Minas Gerais, no ano de 2011. Cienc. Rural, v.45, p.163-170, 2015.

GLONDER, G. Occurence of enterobacteriaceae in feces of granivorous passeriform birds. Avian Dis., v.25, p.195-198, 1981.

GUIDELINES for the placement of confiscated animals. GLAND, SWITZERLAND: IUCN, 2002. Available in: <https://portals.iucn.org/ library/efiles/documents/2002-004.pdf >.

Accessed in: 15 Jan. 2016.

HIDASI, H.W.; MORAES, D.M.C.; LINHARES, G.F.C. et al. Enterobacterial detection and Escherichia coli antimicrobial resistance in parrots seized from the illegal wildlife trade. J. Zoo Wildl. Med., v.44, p.1-7, 2013.

HORN, R.V.; CARDOSO, W.C.; LOPES, E.S. et al. Identification and antimicrobial resistance of members from the Enterobacteriaceae family isolated from canaries (Serinus canaria). Pesqui. Vet. Bras., v.6, p.552-556, 2015.
KONEMAN, E.; WINN, W.J.R.; ALLEN, S. et al. As Enterobacteriaceae. In: Diagnóstico microbiológico: texto e atlas colorido. 6.ed. Rio de Janeiro: Guanabara Koogan, 2012. p.208-299.

LIMA, I.F.N.; BOISEN, N.; QUETZ, J.S. et al. Prevalence of enteroaggregative Escherichia coli and its virulence-related genes in a case-control study among children from north-eastern Brazil. J. Med. Microbiol., v.62, p.683-693. 2013.

LIMA, S.V.G. Pesquisa microbiológica em calopsitas (Nymphicus hollandicus) oriundas de pet shops e residências de Fortaleza, Ceará. 2016. 78f. Dissertação (Mestrado em Ciências Veterinárias) - Faculdade de Medicina Veterinária, Universidade Estadual do Ceará, Fortaleza, CE.

LOPES, E.S.; CARDOSO, W.M.; ALBUQUERQUE, A.H. et al. Isolation of Salmonella spp. em Psittaciformes from zoos and a commercial establishment of Fortaleza, Brazil. Arq. Bras. Med. Vet. Zootec., v.66, p.965-969, 2014.

LOPES, E.S.; MACIEL, W.C.; MACHADO, D.N. et al. Prevalence and antimicrobial resistance profile of enterobacteria isolated from Psittaciformes of illegal wildlife trade. Acta Sci. Vet., v.43, p.1313, 2015

LOPES, E.S.; MACIEL, W.C.; MEDEIROS, P.H.Q. et al. Molecular diagnosis of diarrheagenic Escherichia coli isolated from Psittaciformes of illegal wildlife trade. Pesqui. Vet. Bras., v.38, p.762-766, 2018.

MARIETTO-GONÇALVES, G.A.; ALMEIDA, S.M.; LIMA, E.T.; ANDREATTI-FILHO, R.L. Detecção de Escherichia coli e Salmonella spp. em microbiota intestinal de Psittaciformes em fase de reabilitação para soltura. Braz. J. Res. Anim. Sci., v.47, p.185-189, 2010.

MATIAS, C.A.R.; OLIVEIRA, V.M.; RODRIGUES, D.P.; SICILIANO, S. Summary of the bird species seized in the illegal trade in Rio de Janeiro, Brazil. Traffic Bull., v.24, p.8386, 2012.

MATIAS, C.A.R.; PEREIRA, I.A.; REIS, E.M.F. et al. Frequency of zoonotic bacteria among illegally traded wild birds in Rio de Janeiro. Bras. J. Microbiol., v.47, p.882-888, 2016. 
MENDES, F.L.S. Apreensão de aves silvestres brasileiras que foram exportadas ilegalmente para Portugal. Rev. Bras. Zoociênc., v.19, p.5666, 2018.

OLIVEIRA, E.S.; TORRES, D.F.; ALVES, R.R.N. Wild animals seized in a state in Northeast Brazil: where do they come from and where do they go? Environ. Devel. Sustainability, p.1-21, 2018.

PAGANO, I.S.A.; SOUSA, A.E.A.B.; WAGNER, P.G.C.; RAMOS, R.T.C. Aves depositadas no Centro de Triagem de Animais Silvestres do IBAMA na Paraíba: uma amostra do tráfico de aves silvestres no estado. Ornithologia, v.3, p.132-144, 2009.

PERFORMANCE standards for antimicrobial susceptibility: twenty-second information supplement - document M100-S23. Wayne, PA: Clinical and Laboratory Standards Institute, 2014. Available in: <http://shop.clsi.org/site/ Sample_pdf/M100S25_sample.pdf $>$. Accessed in: 3 Feb. 2016.
REGUEIRA, R.F.S.; BERNARD, E. Wildlife sinks: quantifying the impact of illegal bird trade in street markets in Brazil. Biol. Cons., v.149, p.16-22, 2012.

REPLE, J.N.; OLIVEIRA, M.C.V.; OLIVEIRA, M.G.X. et al. Análise filogenética de Escherichia coli enteropatogênica (EPEC) e produtoras de toxina shiga (STEC) isoladas de fezes de psitacídeos: avaliação do potencial zoonótico. Rev. Educ. Cont. Med. Vet. Zootec., v.13, p.8183, 2015.

TANIUCHI, M.; WALTERS, C.C.; GRATZ, J. et al. Development of a multiplex polymerase chain reaction assay for diarrheagenic Escherichia coli and Shigella spp. and its evaluation on colonies, culture broths, and stool. Diag. Microbiol. Infec. Dis., v.73, p.121-128, 2012. 